\title{
Cardiovascular Complications of Marijuana and Related Substances: A Review
}

\author{
Amitoj Singh · Sajeev Saluja - Akshat Kumar - Sahil Agrawal • \\ Munveer Thind $\cdot$ Sudip Nanda $\cdot$ Jamshid Shirani (D)
}

Received: August 21, 2017 / Published online: December 7, 2017

(c) The Author(s) 2017. This article is an open access publication

\section{ABSTRACT}

The recreational use of cannabis has sharply increased in recent years in parallel with its legalization and decriminalization in several countries. Commonly, the traditional cannabis has been replaced by potent synthetic cannabinoids and cannabimimetics in various forms. Despite overwhelming public perception of the safety of these substances, an increasing number of serious cardiovascular adverse events have been reported in temporal relation to recreational cannabis use. These have included sudden cardiac death, vascular (coronary, cerebral and peripheral) events, arrhythmias and stress cardiomyopathy among others. Many of the victims of these events are relatively young men with few if any cardiovascular risk factors. However, there are reasons to believe that older individuals and those with risk factors for or

Enhanced content To view enhanced content for this article go to http://www.medengine.com/Redeem/ 68FCF06068C10492.

Electronic supplementary material The online version of this article (https://doi.org/10.1007/s40119017-0102-x) contains supplementary material, which is available to authorized users.

A. Singh $\cdot$ S. Saluja $\cdot$ A. Kumar $\cdot$ S. Agrawal .

M. Thind · S. Nanda $\cdot$ J. Shirani ( $ه)$

Department of Cardiology, St. Luke's University

Health Network, Bethlehem, PA, USA

e-mail: jamshid.shirani@sluhn.org established cardiovascular disease are at even higher danger of such events following exposure to cannabis. The pathophysiological basis of these events is not fully understood and likely encompasses a complex interaction between the active ingredients (particularly the major cannabinoid, $\Delta^{9}$-tetrahydrocannabinol), and the endo-cannabinoid system, autonomic nervous system, as well as other receptor and non-receptor mediated pathways. Other complicating factors include opposing physiologic effects of other cannabinoids (predominantly cannabidiol), presence of regulatory proteins that act as metabolizing enzymes, binding molecules, or ligands, as well as functional polymorphisms of target receptors. Tolerance to the effects of cannabis may also develop on repeated exposures at least in part due to receptor downregulation or desensitization. Moreover, effects of cannabis may be enhanced or altered by concomitant use of other illicit drugs or medications used for treatment of established cardiovascular diseases. Regardless of these considerations, it is expected that the current cannabis epidemic would add significantly to the universal burden of cardiovascular diseases.

Keywords: Autonomic nervous system; Cannabis; Endocannabinoid system; Marijuana; Myocardial infarction; Stress 
cardiomyopathy; Stroke; Tetrahydrocannabinol; Vasculopathy

\section{INTRODUCTION}

Cannabis sativa, the plant known as the original marijuana, was likely first cultivated in Central Asia, and subsequently brought to other parts of the world. Currently, cannabis grows naturally in many countries and is also cultivated indoors through the use of hydroponic systems and artificial lighting $[1,2]$. The plant has been long used as a medicinal herb or as a mood altering substance [2]. More recently, a rise in recreational use of cannabis has paralleled that of legislations that have legalized or decriminalized the possession, sales, and cultivation of the plant [3]. According to the United Nations office on drugs and crime, the global recreational use of cannabis increased by $27 \%$ from 1998 to 2009 [1]. In 2014, it was estimated that $\sim 183$ million people use cannabis worldwide with a steady rise since 2007 [4]. Today, cannabis is the most frequently used psychoactive substance after alcohol and tobacco [1]. The recreational cannabis "epidemic" has been accompanied by an increased number of case reports of serious cardiovascular complications from across the globe. A recent systematic review has identified 116 such cases published between January 2011 and March 2016 [5]. In the context of the rising popularity of recreational cannabis (and its synthetic analogues) we aim to review potential cardiovascular adverse events associated with the use of these substances. Furthermore, the potential pathophysiological mechanisms responsible for the most serious cardiovascular events in users of cannabis are discussed.

\section{METHODS}

To prepare this literature review, we performed searches of PUBMED, MEDLINE and EMBASE databases using the phrases "marijuana", "cannabis", "cannabinoids", "THC", " $\Delta$-tetrahydrocannabinol", "cardiovascular disease", "cardiac disease", "heart disease", "stroke", "cannabis arteritis", "stress cardiomyopathy" and "arrhythmia". All referenced material in selected articles were also reviewed carefully for potentially relevant reports. The results were thoroughly examined for accuracy of content. The available literature was then categorized according to both relevance and the clarity of the presented data. Care was particularly taken to avoid inclusion of studies with designs that deviated from usual manners that cannabis is used recreationally. The final count of the manuscripts and documents used was 135 that included 55 case reports, eight case series, 20 human experimental studies, 11 animal or ex vivo studies, 20 databases or guidelines as well as 22 review articles.

\section{Compliance with Ethics Guidelines}

This article does not contain any new studies with human or animal subjects performed by any of the authors.

\section{NATURAL FORMS OF CANNABIS}

In general, three naturally growing strains of Cannabis (sativa, indica, and ruderalis) have been recognized although interbreeding has produced many more "hybrid" strains of the plants. These strains differ in the content and proportion of the two best recognized active ingredients, namely $\Delta^{9}$-tetrahydrocannabinol (THC) and cannabidiol (CBD). Additionally, the effects of various cannabis strains may differ based on the varying concentration and composition of terpene resins [6]. The sativa strain contains the highest level of THC, the psychoactive cannabinoid that produces the euphoric effect and has a relatively low content of CBD, the cannabinoid that may mitigate the euphoric and psychotropic effects of THC. The leaves and buds of the female plants have the highest content of THC and can be dried for smoking or made into other forms of consumable cannabis including edibles, waxes, oils, liquid incense or vapor for both medical and recreational uses. Medically, cannabis has been used effectively for treatment of otherwise refractory nausea and vomiting following chemotherapy and 
neuropathic pain associated with advanced neurologic disorders and cancer, among others $[2,7,8]$. It is important to note that in the United States, cannabis (marijuana) is still listed by the Drug Enforcement Administration as a Schedule I substance, alongside hallucinogens and heroin, according to the section 202 of the Controlled Substances Act of 1970. Schedule I drugs are substances with high potential for abuse, no currently established medical use, and no accepted safety for use under medical supervision. Despite this, 42 states and the District of Columbia have either legalized or decriminalized medical uses of cannabis and related approved medications.

An important consideration in the uses of cannabis has been the unpredictability of the dosage of the active ingredients of variously prepared forms. Accordingly, similar amounts of dried leaves/flowers, waxes/oils, or ingestible forms of cannabis may contain vastly different quantities of active compounds. Additionally, the route of administration may influence the absorption, bioavailability and serum concentration of the active compounds. In a study of healthy volunteers, plasma THC concentration and clinical effects were similar after smoking and intravenous injection while ingestion resulted in less predictable, delayed and lower peak plasma THC concentration [9]. Similar trends have been found for the psychotropic effects of inhaled versus orally ingested THC [10]. The potential physiologic effects of THC are also affected by concomitant use of other illicit drugs, smoking tobacco, and drinking alcohol. The interaction of cannabis with medications used for prevention or treatment of cardiovascular diseases is largely unknown.

There has been an ongoing attempt to standardize the shelf life, dosage and bioavailability of the active compounds contained in naturally derived medical cannabis preparations. One such preparation, nabiximols, a botanical metered dose oral spray that contains both THC and $\mathrm{CBD}$, has been approved in several countries for treatment of spasticity, pain, and urinary dysfunction in multiple sclerosis [7].

\section{SYNTHETIC CANNABINOIDS AND CANNABIMIMETICS}

Synthetic THC compounds, dronabinol and nabilone, have been marketed as capsules in the United States since 1985 for treatment of nausea, vomiting and weight loss associated with cancer chemotherapy and acquired immunodeficiency syndrome. A liquid form of dronabinol has also been approved recently as an oral solution by the United States Food and Drug Administration for anorexia and weight loss associated with acquired immunodeficiency syndrome and refractory nausea/vomiting associated with cancer chemotherapy. Illegally manufactured synthetic cannabinoids and cannabimimetics have been also mass produced for recreational uses and have found appeal among users because they are higher in potency and conventional drug screening tests are unable to identify them. These substances include a family of more than 700 synthetic compounds made by various chemical alterations of THC to enhance its affinity for cannabinoid receptors, augment downstream signal transduction and increase its duration of action. Many synthetic compounds also have highly active metabolites [11]. Synthetic cannabinoids are commonly sprayed onto dried leaves and marketed under various names including Spice and K2.

\section{CARDIOVASCULAR PHYSIOLOGIC EFFECTS OF CANNABINOIDS}

The physiologic effects of cannabis are primarily mediated through the interaction of THC with the endocannabinoid system, an endogenous signaling network involved in a wide range of processes including endothelial function, metabolism, inflammation, and immunity. At least $2 \mathrm{G}$ protein-coupled membrane cannabinoid receptors, CBR1 and CBR2, have been identified. CBR1 is extensively expressed within the central, peripheral sensory and autonomic nervous systems and is the primary target of 
THC. A significant proportion of the cardiovascular effects of cannabinoids are thus mediated through activation of the sympathetic nervous system, as well as inhibition of the parasympathetic autonomic nervous system [12]. Smoking cannabis results in an immediate increase in heart rate that may last more than $1 \mathrm{~h}$ after exposure [13]. This is followed by a substantial rise in serum norepinephrine level at $30 \mathrm{~min}$ [13]. Further support for the role of CBR1-mediated modulation of the autonomic nervous system in the chronotropic response to exogenous cannabinoids is provided by studies that have demonstrated effectiveness of pretreatment with propranolol, atropine, and rimonabant (an inverse agonist of CBR1) in preventing such a response [12, 14-17]. Additionally, inhibition of the parasympathetic activity is suggested by an exaggerated heart rate response to atropine following cannabis smoking [15]. Acute exposure to cannabis may also result in elevation of supine systolic blood pressure $[18,19]$ and may induce atrial fibrillation [20-22]. An epidemiological study has demonstrated an association between elevated systolic pressure and recent use of cannabis [23]. Along with tachycardia and hypertension [12, 24, 25], enhanced left ventricular systolic function as assessed by circumferential fiber shortening (primarily driven by tachycardia) has been reported following the use of cannabis [26]. The summative result of autonomic nervous system modulation by cannabis is an increase in cardiac workload and myocardial oxygen demand. For those who use cannabis by smoking, oxygen delivery to the heart and other vital organs may also be compromised by an elevation in blood carboxyhemoglobin levels [27]. The impaired myocardial oxygen demand to supply ratio following cannabis smoking has been shown to reduce the time to onset of symptoms during exercise in patients with stable angina $[25,28]$. Ventricular fibrillation and appropriate implantable cardioverter defibrillator shock has been reported in a patient with ischemic cardiomyopathy shortly after smoking cannabis [29].

The direct effects of cannabis on regional and organ-level blood flow is complex and likely affected by type and dosage of cannabinoids used, duration of exposure and other external and physiological factors that affect vascular tone. Under controlled experimental conditions, cannabis is believed predominantly to cause an acute vasodilatory response possibly through activation of transient receptor potential ankyrin type-1 (TRPA1) ion channels on perivascular sensory neurons [30]. However, this arteriolar vasodilation is not universal to all vascular beds as vasoconstriction has been seen in the coronary, cerebral and peripheral arterial systems and has been directly responsible for many instances of acute myocardial infarction (AMI), stroke and peripheral arteriopathy $[15,31]$. It has been shown that the contrasting effect of cannabinoids (including THC) in various vascular territories is primarily due to differing endothelial vasodilator mechanisms that exist in these vascular beds $[12,32]$. With respect to coronary circulation, myocardial blood flow, as assessed by ${ }^{13} \mathrm{~N}$-ammonia positron emission tomographic imaging during cold pressor test and after pharmacologic vasodilation, is shown to correlate inversely with circulating plasma levels of endocannabinoids [33]. In addition, cannabis has been shown to be a potent source of cellular oxidative stress through formation of reactive oxygen species [34]. The latter may then contribute to pathogenesis of endothelial dysfunction and promote regional arterial vasospasm through CBR1 receptor-mediated pathway while inhibition of CBR1 is associated with decreased oxidative stress and improved endothelial function [34].

More recently, it was shown that THC prolongs lipopolysaccharide-stimulated tissue factor protein expression in activated monocytes that results in a dose-dependent procoagulant effect [35]. This ex vivo observation has been supported by reports of thrombotic coronary artery occlusion in young individuals without underlying atherosclerosis [36-38]. In addition, both CBR1 and CBR2 are present on the cell membrane of human platelets and exposure to THC is shown to increases the surface expression of glycoprotein IIb-IIIa and $P$ selectin in a concentration-dependent manner [39]. Researchers have further established 


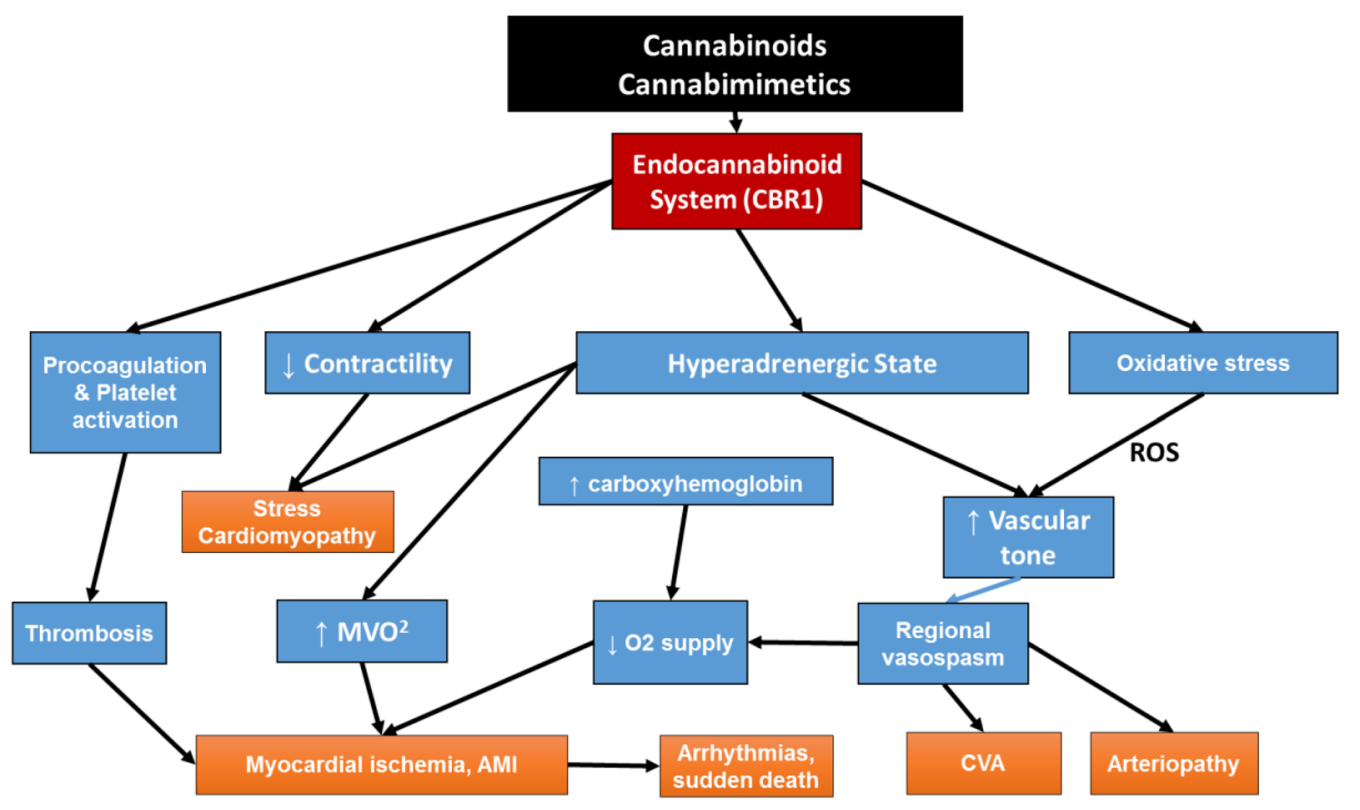

Fig. 1 Flow diagram demonstrating pathophysiologic pathways to common major adverse cardiovascular events reported in users of cannabis and related chemicals. Although non-receptor and non-endocannabinoid receptor-mediated pathways have been identified, most pathologic effects of cannabis are mediated through CBR1. Autonomic nervous system is a major contributor to the pathogenesis of most complications while oxidative stress, hypercoagulability and increased platelet aggregation potentiate such effects. CBR1 activation also has a direct negative inotropic effect on cardiomyocytes and together with catecholamine surge may precipitate stress cardiomyopathy. For those individuals who use cannabis by smoking, elevation of blood carboxyhemoglobin levels may contribute to reduction in oxygen supply to vital organs including the heart. AMI acute myocardial infarction; $C B R 1$ cannabinoid receptor $1, C V A$ cerebrovascular accident, $\mathrm{MVO}_{2}$ myocardial oxygen consumption (demand), $\mathrm{O}_{2}$ oxygen, $\mathrm{ROS}$ reactive oxygen species that cannabinoids exert their effects on platelets through non-receptor mediated pathways as their effect persists in the presence of cannabinoid receptor antagonists [40].

Figure 1 summarizes the cardiovascular physiologic effects of cannabinoids based on human studies and case reports of cardiovascular events observed in temporal relation to marijuana use. Individual major adverse cardiovascular events are subsequently discussed in more detail. Deviations from the scheme proposed in Fig. 1 have been shown in animal studies and in some clinical trials that have used large doses of cannabinoids often administered by unnatural routes. In addition, counter-regulatory mechanisms and tolerance to the effects of cannabinoids exist and may play a role in variable individual responses to these agents.

\section{CARDIOVASCULAR COMPLICATIONS OF CANNABINOID USE}

Adverse cardiovascular effects of cannabis have been suspected for the last 45 years while the last decade has witnessed a sharp rise in the reported incidence of such complications. Between 2006 and 2010, 2\% of all cannabis related events reported to the French Addictovigilance Network were cardiovascular in nature [41]. Furthermore, the cardiovascular complication rate rose from $1.1 \%$ in 2006 to $3.6 \%$ in 2010 and the mortality rate from those complications was 25\% [41]. Cannabis users presenting with cardiovascular emergencies are often young and frequently have no other risk factors for cardiovascular disease [42]. These 
Table 1 Reported adverse cardiovascular events associated with cannabis, synthetic cannabinoids and cannabimimetics

Acute coronary syndrome

Coronary thrombosis without atherosclerosis ${ }^{\mathrm{S} 1-\mathrm{S} 3}$

Recurrent coronary thrombosis ${ }^{S 4}$

Acute myocardial infarction

$$
\text { Non-fatal }{ }^{\text {S5-S8 }}
$$

Fatal $^{\text {S4 }}$

Worsening of stable angina ${ }^{\mathrm{S} 10-\mathrm{S} 12}$

Coronary vasospasm ${ }^{\mathrm{S} 13-\mathrm{S} 18}$

Recurrent coronary vasospasm ${ }^{\text {S19 }}$

Coronary no reflow ${ }^{\mathrm{S} 20, \mathrm{~S} 21}$

Cerebrovascular disease

Ischemic stroke ${ }^{\text {S22-S28 }}$

Recurrent stroke with re-challenge ${ }^{\text {S29 }}$

Stroke with posterior circulation predilection ${ }^{\text {S30, S31 }}$

Cerebral vasospasm ${ }^{\mathrm{S} 32-\mathrm{S} 33}$

Reversible cerebral vasoconstriction syndrome $\mathrm{S}^{\text {S3, S35 }}$

Synthetic cannabinoid and acute cerebrovascular event $^{\text {S36 }}$

Congestive heart failure

Transient left ventricular regional ballooning ${ }^{\text {S37, S38 }}$

Acute congestive heart failure ${ }^{\text {S39 }}$

Synthetic cannabinoids and acute congestive heart failure $^{\mathrm{S} 40, \mathrm{~S} 41}$

Diastolic dysfunction $^{\text {S42 }}$

Rhythm disturbances

Asystole and atrioventricular block ${ }^{\mathrm{S} 43}$

Increase in premature ventricular contractions ${ }^{544}$

Ectopic atrial rhythm ${ }^{\mathrm{S} 45}$

Atrial fibrillation ${ }^{\text {S6, }}$ S47

Ventricular tachycardia ${ }^{\text {S48 }}$

Ventricular fibrillation ${ }^{\text {S49 }}$

Sudden cardiacdeath ${ }^{\mathrm{S50}-\mathrm{S53}}$
Table 1 continued

Vasculopathy

Cannabis arteritis ${ }^{\mathrm{S} 54-\mathrm{S} 57}$

Migratory thrombophlebitis ${ }^{\mathrm{S} 8}$

Renal artery dissection ${ }^{559}$

Central retinal vein occlusion ${ }^{560}$

Fetal cardiovascular complications

Maternal use and single ventricle physiology ${ }^{561}$

Maternal use and transposition of great arteries ${ }^{\mathrm{S} 62}$

Paternal use and membranous ventricular septal defects $^{\text {S63 }}$

Intra-uterine growth retardation ${ }^{\mathrm{S} 64}$

Miscellaneous

Rhabdomyolysis $^{\mathrm{S65}}$

Superscript notations refer to references listed in Supplementary Appendix 1

growing concerns have lead other researchers to call for a registry in the United States similar to the efforts of the French Addictovigilance Network discussed above $[43,44]$. The most commonly reported cardiovascular complications of cannabis use have ranged from acute coronary syndrome (ACS) to cardiac arrhythmias, stroke, peripheral arteriopathy, stress cardiomyopathy (SC) and sudden death (Table 1). Although these adverse events are primarily reported in recreational users of cannabis they have also been observed in those using the cannabis for medically approved reasons.

\section{Acute Coronary Syndrome}

The risk of AMI increases nearly fivefold within an hour of exposure to cannabis compared to nonusers [45]. The population-attributable factor for triggering an AMI by cannabis was found to be relatively low in a meta-analysis of epidemiological studies published between 1960 and 2010 [46]. However, the growing burden of cannabis use and availability of potent synthetic cannabis will likely impact the overall risk of AMI attributable to cannabis. 
Over the last four decades many case reports have temporally linked cannabis use to development of AMI [5]. In some instances, reintroduction of marijuana has also been associated with recurrence of myocardial ischemia [47]. Many, but not all, cannabis users presenting with AMI have been young men with no preexisting coronary artery disease (CAD) and have had normal coronary angiograms $[5,48]$. Toxicology in such cases has often been positive for cannabis only [31, 47-56], although routine urine toxicology may be negative in those using synthetic cannabinoids [57-59]. The latter may have led to significant underestimation of the cannabinoid associated AMI in the young. The pathophysiology of marijuana induced coronary events is shown in Fig. 1 and involves a series of interactions that lead to increased myocardial oxygen demand [60-64], reduced oxygen supply $[28,61,64]$, and a pro-coagulant [35] or pro-thrombotic [36-39] state. In many instances, microvascular $[54,62]$ or epicardial coronary artery spasm $[55,56,63]$ in the absence of atherosclerotic coronary artery disease have been described. In other cases, acute coronary thrombosis in the absence of angiographic atherosclerosis as confirmed by intravascular ultrasonography has been responsible for AMI $[36,37]$. An extreme case of thrombotic total occlusion of the left main requiring emergent coronary artery bypass graft surgery has also been reported [38]. The threshold for precipitation of acute myocardial ischemia is likely lower in cannabis users with established atherosclerotic CAD $[28,64,65]$. In general, AMI in cannabis users may be associated with higher short-term mortality [66]. The latter may in part be related to the potential delay in seeking medical attention in young individuals with impaired judgement due to drug use or to the analgesic effect of cannabis that may mask symptoms [67].

\section{Cerebrovascular Disease}

Reports of acute neurovascular events related to cannabis use have appeared as early as 1964 [68]. A recent systemic review of the literature has firmly concluded that although cannabis use has been linked to several adverse cardiovascular events, the evidence is strongest for ischemic stroke [5]. Neurological symptoms were the most common reasons (44\%) for hospitalization of cannabis users in French healthcare facilities from 2004 to 2007 [69]. Additionally, ischemic stroke is the most commonly reported adverse cardiovascular effect of cannabis use [5]. In a study of young individuals (age 18-44 years) admitted with stroke and substance abuse, cannabis was associated with ischemic but not hemorrhagic events, while amphetamines were associated with predominantly hemorrhagic events [70]. A general population survey of Australians aged $20-64$ years $(n=7455)$, past year cannabis use was associated with a 2.3-fold higher risk of cerebrovascular ischemic events after adjustment for covariates related to stroke including tobacco smoking [71]. The risk was increased to 4.7-fold if the participant used cannabis weekly or more often [71]. Similar results were reported from the United States Nationwide Inpatient Sample, where cannabis use was found to be an independent predictor of acute stroke and associated with a 2.26-fold increased likelihood of hospitalization with acute Ischemic stroke among those aged 25-34 years [72].

Further support for a causal relationship between cannabis use and ischemic stroke comes from numerous case reports over the last three decades [73-75]. A recent series has described 17 cases (age 15-63 years) of ischemic stroke temporally related to cannabis use [76]. Among the latter, five individuals had recurrence of cerebrovascular ischemic symptoms on resuming cannabis use after hospital discharge [76]. Interestingly, the ischemic strokes showed a predilection (53\%) for the posterior cerebral circulation [76]. These observations have been corroborated by other investigators [77, 78]. Although atherosclerosis may be responsible for stroke in some cannabis users, the primary mechanism of stroke in this setting has been reversible cerebrovascular spasm (RCVS) $[79,80]$. RCVS is characterized by severe headache often associated with nausea, vomiting, photophobia, confusion and blurred vision and a "string and beads" appearance of cerebral arteries on angiography [81]. In a prospective 
study of 67 consecutive patients with angiographically confirmed RCVS, $32 \%$ showed positive toxicology for cannabis [81]. In another prospective study of acute ischemic stroke, multifocal narrowing of cerebral arteries (predominantly in posterior circulation) was highly predictive of cannabis use [82]. Reversibility of cerebral vasoconstriction has been demonstrated by angiography within days to months after cessation of cannabis use [82, 83]. It should be noted that similar to AMI, vasospasm is not the sole etiology of ischemic stroke in cannabis users. Transcranial Doppler has demonstrated persistently elevated cerebral vascular resistance in cannabis users even long after monitored abstinence [84]. In a study of 334 of young (age $<45$ years) patients admitted with cannabis related stroke, intracranial arterial stenosis was demonstrated in 45\% [85]. The etiology of stroke in the remaining patients was determined to be cardio-embolic (14\%), presumed paradoxical embolism through an isolated patent foramen ovale (3\%), carotid artery dissection or atherosclerosis (10\%), hypercoagulable state $(3 \%)$ or small vessel disease $(2 \%)$ while the etiology of stroke remained undetermined in nearly one-fourth of the patients [85]. Other potential causes of stroke in cannabis users are cardioembolic events associates with AMI or atrial fibrillation $[86,87]$. Left ventricular apical thrombus has been reported as the etiology of stroke in a young patient with AMI following synthetic cannabinoid use [88].

\section{Left Ventricular Systolic Dysfunction}

The endocannabinoid system is implicated in myocardial stunning associated with acute neurological events, stress (takotsubo) cardiomyopathy, sepsis and hemorrhagic shock [89-92]. Cannabinoids are also shown to reduce myocardial contractility through CBR1-mediated effects [93, 94]. Myocardial dysfunction may also result from persistent tachycardia, atrial fibrillation or induction of ischemia in those with pre-existing CAD [12, 21, 25, 95, 96]. Cannabis use is shown to be an independent predictor of hospitalization with heart failure after adjustment for age, gender, diabetes mellitus, hypertension, CAD, tobacco use, and alcohol use [97]. An association between cannabis use and SC has been shown in case reports [92, 98] and in hospitalized patients [99]. Among the latter, cannabis use was found to be an independent predictor of SC, particularly among younger men, after adjustment for other known risk factors for the disease [96]. Importantly, cannabis users with SC frequently suffered from serious adverse events including cardiac arrest [99].

The pathophysiology of SC in cannabis users remains poorly defined although the associated catecholamine surge may be largely responsible for the association. However, evidence for a primary role of the endocannabinoid system in pathogenesis of stress cardiomyopathy has been mounting. As discussed previously, cannabinoids exert cardiovascular effects and a hyperadrenergic state through receptor-mediated and receptor-independent mechanisms $[12,95,100]$. Endogenous cannabinoids have a CBR1-mediated negative inotropic effect on cardiac muscle [93] and inhibition of CBR1 with rimonabant results in prevention of myocardial dysfunction and myocyte apoptosis after exposure to doxorubicin [94]. It should be noted that the presence of pre-existing myocardial dysfunction may particularly predispose individuals to deterioration of left ventricular systolic function particularly with the use of potent synthetic cannabinoids [101].

\section{Rhythm Disturbances and Sudden Cardiac Death}

An association between cannabis use and palpitation was suggested by an epidemiologic study reported nearly three decades ago [102]. A multitude of case reports have also documented a range of rhythm abnormalities in cannabis users from sinus tachycardia to ectopic atrial or ventricular rhythms, and atrial or ventricular fibrillation [20-22, 29, 103-110]. Logically, these cardiac tachyarrhythmias are explainable by the presence of a hyperadrenergic state following exposure to cannabis and related substances. In fact, electrophysiology study after cannabis use has demonstrated increased 
burden of inducible premature ventricular contractions [111]. Myocardial ischemia caused by microvascular spasm, AMI, or pre-existing CAD may accompany serious ventricular arrhythmias and may result in dizziness, syncope, cardiac arrest or sudden cardiac death [29, 103-110, 112].

Atrial fibrillation has been reported in cannabis users as young as 14 years old and without structural heart disease shortly after smoking cannabis [22, 113]. Cannabis use may also be the sole precipitating factor for atrial fibrillation in the younger $(<45$ years old $)$ individuals and recurrence may occur upon repeated exposure [114]. Atrial fibrillation following cannabis use may be complicated by adverse events due to delayed recognition of the condition in young, otherwise healthy, individuals with altered mental status [114].

\section{Cannabis Arteritis}

Cannabis vasculopathy was first described nearly seven decades ago [115]. Since then, a large number of cases [116-119] and two comprehensive reviews $[120,121]$ have appeared in the literature. The disease is clinically indistinguishable from thromboangiitis obliterans [122-127], but tends to occur at an earlier age in those who use both cannabis and tobacco [128]. The typical angiographic appearance is that of segmental narrowing of distal arteries with minimal if any collateral vessels [127-129]. Subacute and progressive ischemia of upper and lower extremities affected by arteritis may then lead to serious complications including tissue necrosis and gangrene with worsening during periods of heavy cannabis use [130]. Other vascular complications of cannabis use have included migratory thrombophlebitis [131] and renal artery dissection [132]. A rare form of vasculopathy involving occlusion of the central retinal vein has also been reported [133].

\section{CONCLUSIONS}

Cannabis use has rapidly reached epidemic proportions in the world. Appearance of highly potent and unregulated synthetic cannabinoids and cannabimimetics has further complicated the field. Although seriously underestimated and underreported, cardiovascular adverse events are being described at an alarming rate in users of cannabis and its related chemicals. Many of these serious events have occurred in children and young adults who are increasingly driven to use these substances due to the false notion of their safety and rapidly moving decriminalization and legalization processes. The pathophysiology of these adverse cardiovascular events in temporal relation to cannabis is far from established. Yet, the current evidence points to a major role for the endocannabinoid system and its interaction with the autonomic nervous system. Human data is generally deficient and most available studies in humans have been performed decades ago with methodology and resources of the time. While well conducted controlled studies are sorely needed in this area, current data should alert physicians and legislators across the world to the potentially harmful effects of unregulated use of cannabis in children, young adults and those with underlying cardiovascular risk factors or established heart disease.

\section{ACKNOWLEDGEMENTS}

Funding. No funding or sponsorship was received for this study or publication of this article.

Authorship. All named authors meet the International Committee of Medical Journal Editors (ICMJE) criteria for authorship for this manuscript, take responsibility for the integrity of the work as a whole, and have given final approval for the version to be published.

Disclosures. A Singh, S. Saluja, A. Kumar, S. Agrawal, M. Thind, S. Nanda and J. Shirani have nothing to disclose.

Compliance with Ethics Guidelines. This article does not contain any new studies with human or animal subjects performed by any of the authors. 
Open Access. This article is distributed under the terms of the Creative Commons Attribution-NonCommercial 4.0 International License (http://creativecommons.org/licenses/ by-nc/4.0/), which permits any noncommercial use, distribution, and reproduction in any medium, provided you give appropriate credit to the original author(s) and the source, provide a link to the Creative Commons license, and indicate if changes were made.

\section{REFERENCES}

1. United Nations Office on Drugs and Crime (UNODC). World drug report 2016. New York: United Nations Publication; 2016 [Accessed 26 July 2017] p. 174. http://www.unodc.org/doc/wdr2016/ WORLD_DRUG_REPORT_2016_web.pdf.

2. Iversen LL. The science of marijuana. $\mathrm{Br} \mathrm{J}$ Clin Pharmacol. 2009;67:268.

3. Center for Behavioral Health Statistics and Quality. 2015 National survey on drug use and health: detailed tables prevalence estimates. 2016. https:// www.samhsa.gov/data/sites/default/files/NSDUHDetTabs-2016/NSDUH-DetTabs-2016.pdf.

4. Substance Abuse and Mental Health Services Administration. Results from the 2011 national survey on drug use and health: summary of national findings, NSDUH series H-44, HHS publication no. (SMA) 12-4713. Rockville, Maryland: Substance Abuse and Mental Health Services Administrations, 2012.

5. Jouanjus E, Raymond V, Lapeyre-Mestre M, Wolff V. What is the current knowledge about the cardiovascular risk for users of cannabis-based products? A systematic review. Curr Atheroscler Rep. 2017;19:26.

6. Booth JK, Page JE, Bohlmann J. Terpene synthases from Cannabis sativa. PLoS One. 2017;12:e0173911.

7. Koppel BS, Brust JC, Fife T, Bronstein J, Youssof S, Gronseth G, Gloss D. Efficacy and safety of medical marijuana in selected neurologic disorders. Report of the Guideline Development Subcommittee of the American Academy of Neurology. Neurology. 2014;82:1556-63.

8. Iversen L. Cannabis and the brain. Brain. 2003;126:1252-70.

9. Ohlsson A, Lindgren JE, Wahlen A, et al. Plasma delta-9 tetrahydrocannabinol concentrations and clinical effects after oral and intravenous administration and smoking. Clin Pharmacol Ther. 1980;28:409-16.

10. Grotenhermen F. Pharmacokinetics and pharmacodynamics of cannabinoids. Clin Pharmacokinet. 2003;42:327-60.

11. Gurney SMR, Scott KS, Kacinko SL, Presley BC, Logan BK. Pharmacology, toxicology, and adverse effects of synthetic cannabinoid drugs. Forensic Sci Rev. 2014;26:53-78.

12. Benowitz NL, Rosenberg J, Rogers W, Bachman J, Jones RT. Cardiovascular effects of intravenous delta-9-tetrahydrocannabinol: autonomic nervous mechanisms. Clin Pharmacol Ther. 1979;25:440-6.

13. Gash A, Karliner JS, Janowsky D, Lake CR. Effects of smoking marihuana on left ventricular performance and plasma norepinephrine studies in normal men. Ann Intern Med. 1978;89:448-52.

14. Kanakis C Jr, Pouget JM, Rosen KM. The effects of delta-9-tetrahydrocannabinol (cannabis) on cardiac performance with and without beta blockade. Circulation. 1976;53:703-7.

15. Beaconsfield P, Ginsburg J, Rainsbury R. Marihuana smoking: cardiovascular effects in man and possible mechanisms. N Engl J Med. 1972;287:209-12.

16. Sulkowski A, Vachon L, Rich E. Propranolol effects on acute marihuana intoxication in man. Psychopharmacology. 1977;52:47-53.

17. Huestis MA, Boyd SJ, Heishman SJ, Preston KL. Single and multiple doses of rimonabant antagonize acute effects of smoked cannabis in male cannabis users. Psychopharmacology. 2007;194:505-15.

18. Karschner EL, Darwin WD, McMahon RP, Liu F, Wright S, Goodwin RS, et al. Subjective and physiological effects after controlled Sativex and oral THC administration. Clin Pharmacol Ther. 2011;89:400-7.

19. Jicha CJ, Lofwall MR, Nuzzo PA, Babalonis S, Elayi SC, Walsh SL. Safety of oral dronabinol during opioid withdrawal in humans. Drug Alcohol Depend. 2015;157:179-83.

20. Charbonney E, Sztajzel JM, Poletti PA, Rutschmann O. Paroxysmal atrial fibrillation after recreational marijuana smoking: another "holiday heart"? Swiss Med Wkly. 2005;135:412-4.

21. Kosior DA, Filipiak KJ, Stolarz P, Opolski G. Paroxysmal atrial fibrillation following marijuana intoxication: a two-case report of possible association. Int J Cardiol. 2001;78:183-4. 
22. Singh GK. Atrial fibrillation associated with marijuana use. Pediatr Cardiol. 2000;21:284.

23. Ponto LL, O'Leary DS, Koeppel J, et al. Effect of acute marijuana on cardiovascular function and central nervous system pharmacokinetics of $\left[{ }^{(15)} \mathrm{O}\right]$ water: effect in occasional and chronic users. J Clin Pharmacol. 2004;44:751-66.

24. Alshaarawy O, Elbaz HA. Cannabis use and blood pressure levels: United States National Health and Nutrition Examination Survey, 2005-2012. J Hypertens. 2016;34:1507-12.

25. Prakash R, Aronow WS, Warren M, et al. Effects of marihuana and placebo marihuana smoking on hemodynamics in coronary disease. Clin Pharmacol Ther. 1975;18:90-5.

26. Tashkin DP, Levisman JA, Abbasi AS, Shapiro BJ, Ellis NM. Short-term effects of smoked marihuana on left ventricular function in man. Chest. 1977;72:20-6.

27. Wu TC, Tashkin DP, Djahed B, Rose JE. Pulmonary hazards of smoking marijuana as compared with tobacco. N Engl J Med. 1988;318:347-51.

28. Aronow WS, Cassidy J. Effect of marihuana and placebo-marihuana smoking on angina pectoris. N Engl J Med. 1974;291:65-7.

29. Baranchuk A, Johri AM, Simpson CS, Methot M, Redfearn DP. Ventricular fibrillation triggered by marijuana use in a patient with ischemic cardiomyopathy: a case report. Cases J. 2008;1:373.

30. Jordt SE, Bautista DM, Chuang HH, McKemy DD, Zygmunt PM, Högestätt ED, Meng ID, Julius D. Mustard oils and cannabinoids excite sensory nerve fibres through the TRP channel ANKTM1. Nature. 2004;427:260-5.

31. Dines AM, Wood DM, Galicia M, Yates CM, Heyerdahl F, Hovda KE, et al. Presentations to the emergency department following cannabis use-a multi-centre case series from ten European countries. J Med Toxicol. 2015;11(4):415-21.

32. O'Sullivan SE, Kendall DA, Randall MD. Further characterization of the time-dependent vascular effects of delta9-tetrahydrocannabinol. J Pharmacol Exp Ther. 2006;317:428-38.

33. Quercioli A, Pataky Z, Vincenti G, et al. Elevated endocannabinoid plasma levels are associated with coronary circulatory dysfunction in obesity. Eur Heart J. 2011;32:1369-78.

34. Lipina C, Hundal HS. Modulation of cellular redox homeostasis by the endocannabinoid system. Open Biol. 2016;6:150276.
35. Williams JC, Klein TW, Goldberger BA, Sleasman JW, Mackman N, Goodenow MM. $\Delta(9)$-Tetrahydrocannabinol (THC) enhances lipopolysaccharidestimulated tissue factor in human monocytes and monocyte-derived microvesicles. J Inflamm (Lond). 2015;12:39.

36. Dahdouh Z, Roule V, Lognoné T, Sabatier R, Grollier G. Cannabis and coronary thrombosis: what is the role of platelets? Platelets. 2012;23:243-5.

37. Hodcroft CJ, Rossiter MC, Buch AN. Cannabis-associated myocardial infarction in a young man with normal coronary arteries. J Emerg Med. 2014;47:277-81.

38. Velibey Y, Sahin S, Tanık O, Keskin M, Bolca O, Eren M. Acute myocardial infarction due to marijuana smoking in a young man: guilty should not be underestimated. Am J Emerg Med. 2015;33:1114.e1-3.

39. Deusch E, Kress HG, Kraft B, Kozek-Langenecker SA. The procoagulatory effects of delta-9-tetrahydrocannabinol in human platelets. Anesth Analg. 2004;99:1127-30.

40. Brantl SA, Khandoga AL, Siess W. Mechanism of platelet activation induced by endocannabinoids in blood and plasma. Platelets. 2014;25:151-61.

41. Jouanjus E, Lapeyre-Mestre M, Micallef J. Cannabis use: signal of increasing risk of serious cardiovascular disorders. J Am Heart Assoc. 2014;3:e000638.

42. Lindsay AC, Foale RA, Warren O, Henry JA. Cannabis as a precipitant of cardiovascular emergencies. Int J Cardiol. 2005;104:230-2.

43. Rezkalla S, Kloner RA. Recreational marijuana use: is it safe for your patient? J Am Heart Assoc. 2014;3:e000904.

44. Rezkalla S, Stankowski R, Kloner RA. Cardiovascular effects of marijuana. J Cardiovasc Pharmacol Ther. 2016;21:452-5.

45. Mittleman MA, Lewis RA, Maclure M, Sherwood JB, Muller JE. Triggering myocardial infarction by marijuana. Circulation. 2001;103:2805-9.

46. Nawrot TS, Perez L, Künzli N, Munters E, Nemery B. Public health importance of triggers of myocardial infarction: a comparative risk assessment. Lancet. 2011;377:732-40.

47. Safaa AM, Markham R, Jayasinghe R. Marijuana-induced recurrent acute coronary syndrome with normal coronary angiograms. Drug Alcohol Rev. 2012;31:91-4.

48. Caldicott DG, Holmes J, Roberts-Thomson KC, Mahar L. Keep off the grass: marijuana use and 
acute cardiovascular events. Eur J Emerg Med. 2005;12:236-44.

49. Tatli E, Yilmaztepe M, Altun G, et al. Cannabis-induced coronary artery thrombosis and acute anterior myocardial infarction in a young man. Int $\mathrm{J}$ Cardiol. 2007;120:420-2.

50. Cappelli F, Lazzeri C, Gensini GF, et al. Cannabis: a trigger for acute myocardial infarction? A case report. J Cardiovasc Med (Hagerstown). 2008;9:725-8.

51. Yurtdaş M, Aydın MK. Acute myocardial infarction in a young man; fatal blow of the marijuana: a case report. Korean Circ J. 2012;42:641-5.

52. Pratap B, Korniyenko A. Toxic effects of marijuana on the cardiovascular system. Cardiovasc Toxicol. 2012;12:143-8.

53. Arora S, Goyal H, Aggarwal P, Kukar A. ST-segment elevation myocardial infarction in a 37-year-old man with normal coronaries-it is not always cocaine! Am J Emerg Med. 2012;30:2091.e3.

54. Karabulut A, Cakmak M. ST segment elevation myocardial infarction due to slow coronary flow occurring after cannabis consumption. Kardiol Pol. 2010;68:1266-8.

55. Casier I, Vanduynhoven P, Haine S, Vrints C, Jorens PG. Is recent cannabis use associated with acute coronary syndromes? An illustrative case series. Acta Cardiol. 2014;69:131-6.

56. Gunawardena MDVM, Rajapakse S, Herath J, Amarasena N. Myocardial infarction following cannabis induced coronary vasospasm. BMJ Case Rep. 2014;2014. https://doi.org/10.1136/bcr-2014207020.

57. Mir A, Obafemi A, Young A, Kane C. Myocardial infarction associated with use of the synthetic cannabinoid K2. Pediatrics. 2011;128:e1622-7.

58. Atik SU, Dedeoglu R, Varol F, Cam H, Eroglu AG, Saltik L. Cardiovascular side effects related with use of "bonzai": two case reports. Turk Arch Pediatr. 2015;50:61-4.

59. McKeever RG, Vearrier D, Jacobs D, LaSala G, Okaneku J, Greenberg MI. K2-not the spice of life; synthetic cannabinoids and ST elevation myocardial infarction: a case report. J Am Coll Med Toxicol. 2015;11:129-31.

60. Jones RT. Cardiovascular system effects of marijuana. J Clin Pharmacol. 2002;42(11 Suppl): 58S-63S.

61. Ashton $\mathrm{CH}$. Pharmacology and effects of cannabis: a brief review. Br J Psychiatry. 2001;178:101-6.
62. Rezkalla SH, Sharma P, Kloner RA. Coronary no-flow and ventricular tachycardia associated with habitual marijuana use. Ann Emerg Med. 2003;42:365-9.

63. Basnet S, Mander G, Nicolas R. Coronary vasospasm in an adolescent resulting from marijuana use. Pediatr Cardiol. 2009;30:543-5.

64. Aronow WS, Cassidy J. Effect of smoking marihuana and of a high-nicotine cigarette on angina pectoris. Clin Pharm Therap. 1975;17:549-54.

65. Gottschalk LA, Aronow WS, Prakash R. Effect of marijuana and placebo-marijuana smoking on psychological state and on psycho-physiological cardiovascular functioning in anginal patients. Biol Psychiatry. 1977;12:255-66.

66. Mukamal KJ, Maclure M, Muller JE, Mittleman MA. An exploratory prospective study of marijuana use and mortality following acute myocardial infarction. Am Heart J. 2008;155:465-70.

67. Hall W, Solowij N. Adverse effects of cannabis. Lancet. 1998;352:1611-6.

68. Mohan H, Sood GC. Conjugate deviation of the eyes after Cannabis indica intoxication. Br J Ophthalmol. 1964;48:160-1.

69. Jouanjus E, Leymarie F, Tubery M, et al. Cannabisrelated hospitalizations: unexpected serious events identified through hospital databases. Br J Clin Pharmacol. 2011;71:758-65.

70. Westover AN, McBride S, Haley RW. Stroke in young adults who abuse amphetamines or cocaine: a population-based study of hospitalized patients. Arch Gen Psychiatry. 2007;64:495-502.

71. Hemachandra D, McKetin R, Cherbuin N, Anstey KJ. Heavy cannabis users at elevated risk of stroke: evidence from a general population survey. Aust $\mathrm{N}$ Z J Public Health. 2016;40:226-30.

72. Rumalla K, Reddy AY, Mittal MK. Recreational marijuana use and acute ischemic stroke: a population-based analysis of hospitalized patients in the United States. J Neurol Sci. 2016;364:191-6.

73. Phillips MC, Leyden JM, Chong WK, et al. Ischaemic stroke among young people aged 15 to 50 years in Adelaide, South Australia. Med J Aust. 2011;195:610-4.

74. de los Ríos F, Kleindorfer DO, Khoury J, et al. Trends in substance abuse preceding stroke among young adults: a population based study. Stroke. 2012;43:3179-83.

75. Wolff V, Armspach JP, Lauer V, et al. Cannabis-related stroke: myth or reality? Stroke. 2013;44:558-63. 
76. Singh NN, Pan Y, Muengtaweeponsa S, Geller TJ, Cruz-Flores S. Cannabis-related stroke: case series and review of literature. J Stroke Cerebrovasc Dis. 2012;21:555-60.

77. Finsterer J, Christian P, Wolfgang K. Occipital stroke shortly after cannabis consumption. Clin Neurol Neurosurg. 2004;106:305-8.

78. Santos AF, Rodriguez M, Maré R, Ferreira C, SoaresFernandes J, Rocha J. Recurrent stroke in a young cannabis user. J Neuropsychiatry Clin Neurosci. 2014;26:41-2.

79. Mouzak A, Agathos P, Kerezoudi E, Mantas A, Vourdeli-Yiannakoura E. Transient ischemic attack in heavy cannabis smokers-how "safe" is it? Eur Neurol. 2000;44:42-4.

80. Melki E, Denier C, Théaudin-Saliou M, Sachet M, Ducreux D, Saliou G. External carotid artery branches involvement in reversible cerebral vasoconstriction syndrome. J Neurol Sci. 2012;313:46-7.

81. Ducros A, Boukobza M, Porcher R, Sarov M, Valade $\mathrm{D}$, Bousser MG. The clinical and radiological spectrum of reversible cerebral vasoconstriction syndrome. A prospective series of 67 patients. Brain. 2007;130:3091-101.

82. Wolff V, Lauer V, Rouyer O, Sellal F, Meyer N, Raul JS, et al. Cannabis use, ischemic stroke, and multifocal intracranial vasoconstriction a prospective study in 48 consecutive young patients. Stroke. 2011;42:1778-80.

83. Uhegwu N, Bashir A, Hussain M, Dababneh $H$, Misthal S, Cohen-Gadol A. Marijuana induced reversible cerebral vasoconstriction syndrome. J Vasc Interv Neurol. 2015;8:36-8.

84. Herning RI, Better WE, Tate K, Cadet JL. Cerebrovascular perfusion in marijuana users during a month of monitored abstinence. Neurology. 2005;64:488-93.

85. Wolff V, Zinchenko I, Quenardelle V, Rouyer O, Geny B. Characteristics and prognosis of ischemic stroke in young cannabis users compared with noncannabis users. J Am Coll Cardiol. 2015;66:2052-3.

86. Renard D, Taieb G, Gras-Combe G, Labauge P. Cannabis-related myocardial infarction and cardioembolic stroke. J Stroke Cerebrovasc Dis. 2012;21:82-3.

87. Volpon LC, Sousa CLMM, Moreira SKK, Teixeira SR, Carlotti APCP. Multiple cerebral infarcts in a young patient associated with marijuana use. J Addict Med. 2017;11:405-7.

88. Shah M, Garg J, Patel B, Guthier J, Freudenberger RS. Can your heart handle the spice: a case of acute myocardial infarction and left ventricular apical thrombus. Int J Cardiol. 2016;215:129-31.

89. Wagner JA, Varga K, Ellis EF, Rzigalinski BA, Martin BR, Kunos G. Activation of peripheral CB1 cannabinoid receptors in hemorrhagic shock. Nature. 1997;390:518-21.

90. Varga K, Wagner JA, Bridgen DT, Kunos G. Plateletand macrophage-derived endogenous cannabinoids are involved in endotoxin-induced hypotension. FASEB J. 1998;12:1035-44.

91. Godlewski G, Malinowska B, Schlicker E. Presynaptic cannabinoid $\mathrm{CB}(1)$ receptors are involved in the inhibition of the neurogenic vasopressor response during septic shock in pithed rats. Br J Pharmacol. 2004;142:701-8.

92. Kaushik M, Alla VM, Madan R, Arouni AJ, Mohiuddin SM. Recurrent stress cardiomyopathy with variable regional involvement: insights into etiopathogenetic mechanisms. Circulation. 2011;124:e556-7.

93. Bonz A, Laser M, Küllmer S, et al. Cannabinoids acting on CB1 receptors decrease contractile performance in human atrial muscle. J Cardiovasc Pharmacol. 2003;41:657-64.

94. Mukhopadhyay P, Bátkai S, Rajesh M, et al. Pharmacological inhibition of CB1 cannabinoid receptor protects against doxorubicin-induced cardiotoxicity. J Am Coll Cardiol. 2007;50:528-36.

95. Pacher P, Bátkai S, Kunos G. Cardiovascular pharmacology of cannabinoids. Handb Exp Pharmacol. 2005;168:599-625.

96. Sidney S. Cardiovascular consequences of marijuana use. J Clin Pharmacol. 2002;42(S1):64S-70S.

97. Kalla A, Krishnamoorthy P, Gopalakrishnan A, Garg $\mathrm{J}$, Figueredo V. Cannabis use predicts risks of heart failure and cerebrovascular accidents: results from the national inpatient sample. J Am Coll Cardiol. 2017;69(11(Suppl)):1784 (abstract).

98. Nogi M, Fergusson D, Chiaco JM. Mid-ventricular variant takotsubo cardiomyopathy associated with cannabinoid hyperemesis syndrome: a case report. Hawaii J Med Public Health. 2014;73:115-8.

99. Singh A, Agrawal S, Fegley M, Manda Y, Nanda S, Shirani J. Marijuana (cannabis) use is an independent predictor of stress cardiomyopathy in younger men. Circulation. 2016;134:A14100.

100. Pacher P, Mukhopadhyay P, Mohanraj R, Godlewski G, Bátkai S, Kunos G. Modulation of the endocannabinoid system in cardiovascular disease: therapeutic potential and limitations. Hypertension. 2008;52:601-7. 
101. Elsheshtawy M, Sriganesh P, Virparia V, Patel F, Khanna A. Synthetic marijuana induced acute nonischemic left ventricular dysfunction. Case Rep Cardiol. 2016;2016:4. https://doi.org/10.1155/ $2016 / 9625758$.

102. Petronis KR, Anthony JC. An epidemiologic investigation of marijuana- and cocaine-related palpitations. Drug Alcohol Depend. 1989;23:219-26.

103. Kiplinger GF, Manno JE. Dose-response relationships to cannabis in human subjects. Pharmacol Rev. 1971;23:339-47.

104. Daisley H, Jones-Le Cointe A, Hutchinson G, Simmons V. Fatal cardiac toxicity temporally related to poly-drug abuse. Vet Hum Toxicol. 1998;40:21-2.

105. Bachs L, Mørland H. Acute cardiovascular fatalities following cannabis use. Forensic Sci Int. 2001;124:200-3.

106. Montisci M, Thiene G, Ferrara SD, Basso C. Cannabis and cocaine: a lethal cocktail triggering coronary sudden death. Cardiovasc Pathol. 2008;17:344-6.

107. Fernández- Fernández FJ, Caínzos-Romero T, Mesías Prego A, Sesma P. Ectopic atrial rhythm associated with cannabis use. Minerva Cardioangiol. 2011;59:119-20.

108. Hartung B, Kauferstein S, Ritz-Timme S, Daldrup T. Sudden unexpected death under acute influence of cannabis. Forensic Sci Int. 2014;237:e11-3.

109. Korantzopoulos P, Liu T, Papaioannides D, Li G, Goudevenos JA. Atrial fibrillation and marijuana smoking. Int J Clin Pract. 2008;62:308-13.

110. Krishnamoorthy S, Lip GY, Lane DA. Alcohol and illicit drug use as precipitants of atrial fibrillation in young adults: a case series and literature review. Am J Med. 2009;122:851-6.

111. Miller RH, Dhingra RC, Kanakis C, Amat-y-Leon F, Rosen KM. The electrophysiological effects of delta9-tetrahydrocannabinol (cannabis) on cardiac conduction in man. Am Heart J. 1977;94:740-7.

112. Orsini J, Blaak C, Rajayer S, Gurung V, Tam E, Morante J, Shamian B, Malik R. Prolonged cardiac arrest complicating a massive ST-segment elevation myocardial infarction associated with marijuana consumption. J Community Hosp Intern Med Perspect. 2016; . https://doi.org/10.3402/jchimp.v6.31695.

113. Fisher BAC, Ghuran A, Vadamalai V, Antonios TF. Cardiovascular complications induced by cannabis smoking: a case report and review of the literature. Emerg Med J. 2005;22:679-80.
114. Korantzopoulos P. Marijuana smoking is associated with atrial fibrillation. Am J Cardiol. 2014;113:1085-6.

115. Sterne J, Ducasting G. Les artérites du Cannabis indica. Arch Mal Cour. 1960;53:143-7.

116. Bucci F, Redler A, Fiengo L. Critical limb ischemia in a young man: saddle embolism or unusual presentation of thromboangiitis obliterans? Case Rep Vasc Med. 2013;2013:4. https://doi.org/10.1155/2013/ 830540

117. Broz P, Jaeger KA. Images in vascular medicineBuerger's disease. Vasc Med. 2012;17:366-7.

118. Ibrir M, Ouadahi N, Hamzaoui N, Zemmour D, Ghita DH, Habouchi A, et al. Peripheral arteritis disease and ischemic strokes in cannabis use: a case report. Thromb Res. 2014;133:S115-6.

119. Roberts JA, Meyer J-P. Buerger's disease presenting as a testicular mass: a rare presentation of an uncommon disease. Urol Ann. 2016;8:249-51.

120. Combemale P, Consort T, Denis-Thelis L, Estival JL, Dupin M, Kanitakis J. Cannabis arteritis. Br J Dermatol. 2005;152:166-9.

121. Cottencin O, Karila L, Lambert M, Arveiller C, Benyamina A, Boissonas A, Goudemand M, Reynaud M. Cannabis arteritis: review of the literature. J Addict Med. 2010;4:191-6.

122. Leithauser B, Langheinrich AC, Rau WS, Tillmanns $\mathrm{H}$, Matthias FR. A 22-year-old woman with lower limb arteriopathy: Buerger's disease, or methamphetamine or cannabis-induced arteritis? Heart Vessels. 2005;20:39-43.

123. Peyrot I, Garsaud AM, Saint-Cyr I, Quitman O, Sanchez B, Quist D. Cannabis arteritis: a new case report and a review of the literature. J Eur Acad Dermatol Venereol. 2007;21:388-91.

124. Nahas GG. Cannabis arteritis. $N$ Engl J Med. 1971;284:113.

125. Cazalets C, Laurat E, Cador B, et al. Arteriopathies du cannabis: quatre nouveaux cas [Cannabis arteritis: four new cases]. Rev Med Intern. 2003;24:127-30.

126. Martin-Blondel G, Koskas F, Cacoub P, Sène D. Is thrombangitis obliterans presentation influenced by cannabis addiction? Ann Vasc Surg. 2011;25:469-73.

127. Noel B, Ruf I, Panizzon RG. Cannabis arteritis. J Am Acad Dermatol. 2008;58(Suppl 1):S65-7. 
128. Schneider F, Abdoucheli-Baudot N, Tassart M, et al. Cannabis and tobacco: cofactors favoring juvenile obliterative arteriopathy. J Mal Vasc. 2000;25:388-9.

129. Santos RP, Resende CI, Vieira AP, Brito C. Cannabis arteritis: ever more important to consider. BMJ Case Rep. 2017;2017. https://doi.org/10.1136/bcr-2016219111.

130. Disdier P, Granel B, Serratrice J, et al. Cannabis arteritis revisited-ten new case reports. Angiology. 2001;52:1-5.
131. Lee C, Moll S. Migratory superficial thrombophlebitis in a cannabis smoker. Circulation. 2014;130:214-5.

132. Lou JY, Randhawa MS, Hornacek D, Bajzer C. Spontaneous renal artery dissection in a cannabis user. Vasc Med. 2015;20:379-80.

133. Corvi F, Querques G, Lattanzio R, Preziosa C, Parodi $\mathrm{MB}$, Bandello $\mathrm{F}$. Central retinal vein occlusion in a young patients following cannabis smoke inhalation. Eur J Ophthalmol. 2014;24(3):437-40. 